\title{
Research in Clinical Laboratory Science: Professionals' Involvement
}

\section{REBECCA LAUDICINA, JOANN FENN, VICKIE FREEMAN, CAROL MCCOY, MARY ANN MCLANE, LILLIAN MUNDT, JOAN POLANCIC, TIM RANDOLPH, KRISTY SHANAHAN}

\section{LEARNING OBJECIVES}

1. Identify CLS practitioners' sources of knowledge of research principles and hands-on research training.

2. List activities that CLS practitioners believe would help improve their research skills.

3. Describe research components of CLS educational programs.

4. Characterize activities included in CLS undergraduate and master's student research projects.

5. List perceived barriers to research participation by undergraduates and master's students in CLS educational programs.

OBJECTIVES: To describe current qualitative and quantitative aspects of research engagement and other scholarly activities conducted by clinical laboratory science (CLS) professionals across a range of employment settings.

DESIGN: A link to a 3-part online survey was sent by electronic mail to 7,572 members of the American Society for Clinical Laboratory Science and 500 program directors.

SETTING: email message, on-line survey

PARTICIPANTS: all ASCLS members and all directors of accredited clinical laboratory educational programs

MAIN OUTCOME MEASURES: Quantitative and qualitative measures of professionals' engagement in research and other scholarly activities

RESULTS: 556 of 7572 (7.3\%) persons completed the survey. Thirty-two percent of survey respondents reported spending between 1 to $>40$ work hours per week conducting research with $68 \%$ of respondents not participating in research activities. Conducting research is an employment requirement for $18 \%$ of survey participants. Twenty-nine percent of respondents have published at least one research article, and $47 \%$ of respondents who conduct research have published studies in the journal Clinical Laboratory Science. More than $57 \%$ of respondents participate in non-research scholarly activities as part of their employment. CLS professionals who conduct research are more likely to do applied, clinical, or educational research than other types of research. Fifty-seven percent of respondents who conduct research lack external funding for their work. Ninety-three percent of total research dollars is obtained by respondents who hold the Ph.D. degree. The perception of the importance of conducting research varies by employment position. Barriers to participation in research include lack of inclusion of research in the job description, time constraints, inadequate research funding, limited opportunity, and lack of space and equipment.

CONCLUSIONS: CLS professionals participate in research in limited numbers, and are more likely to engage in non-research types of scholarly activities. Numerous barriers are identified which impose limits to conducting research. Over half of CLS's research efforts lack external funding. Although there was broad representation among participants across educational levels, employment settings, and job positions, the number of survey respondents was limited. Possible directions for future research include conducting this survey using members of additional professional organizations. 


\section{FOCUS: BUILDING RESEARCH THROUGH MLS CURRICULA}

ABBREVIATIONS: CLS = clinical laboratory science; ASCLS = American Society for Clinical Laboratory Science; NAACLS = National Accrediting Agency for Clinical Laboratory Science

INDEX TERMS: research activity, education

Clin Lab Sci 2011;24(4):235

JoAnn P. Fenn, M.S., MT(ASCP), Department of Pathology, University of Utah School of Medicine, Salt Lake City, UT

Vickie Freeman, Ph.D., MLS(ASCP) ${ }^{C M} S C, F A C B$, University of Texas Medical Branch, Galveston, TX

Carol McCoy, Ph.D., MLS(ASCP $)^{C M}$, Fairview Health Services. Minneapolis, $M N$

Mary Ann McLane, Ph.D., MLS(ASCP) ${ }^{C M}$, University of Delaware, Newark, DE

Lillian A. Mundt, Ed.D., MLS(ASCP)SH, Adventists Health System Midwest, Hinsdale, IL

Joan Polancic, M.S.Ed., MLS, American Society for Clinical Laboratory Science, Washington, DC

Tim Randolph, Ph.D., MLS(ASCP), Saint Louis University, Saint Louis, $M O$

Kristy Shanahan, M.S., MLS(ASCP $)^{C M}$, Rosalind Franklin University of Medicine and Science, North Chigaco, IL

Address for Correspondence: Rebecca Laudicina, Ph.D., MLS(ASCP $)^{C M}$, The University of North Carolina at Chapel Hill, 4110 Bondurant Hall, CB\# 7145, Chapel Hill, NC 27599-7145, (919) 8434350,rebecca_laudicina@med.unc.edu

\section{INTRODUCTION}

A task force consisting of nine members of the American Society for Clinical Laboratory Science (ASCLS) was created in October 2008 by the ASCLS leadership, including ASCLS president-elect Mary Ann McLane. The task force was charged with studying the state of research in the clinical laboratory science profession. At that time there was a perceived need for increased attention focused on research related to the practice of clinical laboratory science, especially by members of the profession. In creating the task force, Dr. McLane's overall goals were to highlight members' research efforts, to encourage research efforts and promote collaborations, and to increase the quantity and level of research.

The specific charges to the ASCLS Research Task Force members were to: ${ }^{1}$

- Raise awareness of the need to do research in clinical laboratory science.

- Portray the state of research funding, including sources and amounts.

- Describe the type of research being conducted, e.g., clinical or basic science research.

The ASCLS Research Task Force, consisting of members from various institutions, met for several months through conference telephone calls from 2008 to 2009. The Research Task Force developed a three part survey consisting of 42 items. The first section was to be completed by all participants and assessed demographic characteristics of participants, opinions about research, involvement in research, and barriers to conducting research. Section 2 was to be completed only by CLS professionals who were currently doing research or had done research in the past. Section 3 was targeted to program directors of CLS undergraduate and graduate programs, and results of this section are included in a separate article. A 3 section online survey using the SurveyMonkey ${ }^{\mathrm{TM}}$ platform was developed reflecting all study objectives. Survey distribution and results analysis were sponsored by ASCLS.

Studying scholarly activities of clinical laboratory science (CLS) program faculty is one approach traditionally used to assess the state of research within the profession. Waller and colleagues surveyed four-year college and university CLS faculty in 2008. They reported that $52 \%$ of CLS faculty held doctorates, and that faculty holding doctorates spent more time conducting research and received more funding than faculty with bachelor of science (B.S.) or master of science (M.S.) degrees. The numbers of research publications were greater for professors than for assistant and associate professors and instructors, and the numbers were greater for tenured or tenure track 


\section{FOCUS: BUILDING RESEARCH THROUGH MLS CURRICULA}

faculty than for faculty not in a tenure system. Total grant funding by faculty was reported as $\$ 62$ million. Twenty-nine percent of faculty spent no time doing research, 36\% had never published a research article or abstract, and $24 \%$ had never given a presentation. Teaching was rated as "most important" in their institution by $66 \%$ of respondents, while research was rated as "most important" by $31 \%$ of respondents. In comparing the data collected in 2008 to data from similar studies conducted in 1985 and 1999, increases were observed in the number of publications in research journals, number of presentations, and number of CLS faculty holding doctorates. Waller and colleagues concluded that progress has been made by CLS faculty in advancing the profession and fulfilling academic missions through research. ${ }^{2}$

A 2009 study by Mundt and Shanahan assessed perceptions held by ASCLS members regarding the importance of research. Over 99\% of survey respondents believed that research based on studying clinical laboratory specimens yields important information, contributes to the body of knowledge in clinical laboratory science, and improves patient care. Seventy-five percent of respondents believe that research opportunities exist in the clinical laboratory setting, but $69 \%$ disagreed that adequate resources exist for conducting research. Eighty-three percent feel there is inadequate time available for research in the clinical setting. Approximately $75 \%$ of respondents believe that laboratory professionals have the responsibility to conduct research, publish their studies, and present their findings at meetings of professional societies. However, $71 \%$ of professionals state they are unlikely to publish research findings on their own, and 53\% state they are unlikely to present their findings at a national meeting. Participants in this survey held a variety of academic degrees, including 51\% B.S., 31\% M.S., and $9 \%$ doctoral degrees. Participants rated the relevance of various laboratory activities to research, generating a broad list of potential scholarly activities for laboratory practitioners. $^{3}$

Because there is a paucity of published data characterizing quantitative and qualitative research and non-research scholarship in the CLS profession, studies of other health-related disciplines were consulted. The need to examine and possibly increase research productivity is not limited to CLS, but appears to be shared by other health-related disciplines, including nursing, dentistry, medicine, and pharmacy. Barriers to faculty scholarship in these professions, identified by Smesny et al, include time limitations imposed by expected participation in clinical service and teaching, lack of role models and mentors for younger faculty members, and failure to acknowledge alternative forms of scholarship. ${ }^{4}$

Riley et al argue for an expanded approach to scholarship in nursing, in which scholarship is viewed as a responsibility of both the profession collectively and of individual nurses in clinical practice settings. ${ }^{5}$ Fonteyn and colleagues found that scholarly activity by oncology nurses in a variety of practice roles was augmented through a structured workplace program of mentoring, regular meetings, and professional development sessions. Abstract submissions, posters, and presentations at national meetings increased for the program participants. ${ }^{6}$

The work of educator Ernest Boyer provides an underlying theme for conceptualizing scholarship within the discipline of clinical laboratory science (CLS). While a traditional approach defines scholarship as development of new knowledge that resides predominantly within an academic setting, Boyer expands scholarship to include the integration, application, and teaching of knowledge. In healthcare disciplines such as CLS, these latter aspects of scholarship may be more relevant to clinical settings than traditional research, thereby focusing on the contributions made by practitioners rather than academicians. For that reason the present study has assumed a broad and inclusive approach to scholarship, acknowledging both research and non-research activities. $^{7}$

\section{MATERIALS AND METHODS}

Instructions and a link to an online 42-item survey developed by the ASCLS Research Task Force were emailed in May 2009 to 7,572 individuals who were either members of the American Society for Clinical Laboratory Science or program directors of NAACLS accredited two-year, four-year, and graduate educational programs. A second email message was sent to the mailing list as a reminder prior to the survey closing. Data from the survey results were collected following closing of survey availability one month later. There was 


\section{FOCUS: BUILDING RESEARCH THROUGH MLS CURRICULA}

no attempt to collect or retain participant identifiers in this study. The study was approved by the University of Utah Institutional Review Board.

\section{RESULTS}

Section 1. Demographics and general questions about research

Completion of the 19 items in this section was requested of all survey participants. Responses to the online survey were received from 556 persons, or $7 \%$ of those surveyed. Females comprised $83 \%$ of the sample. Eighty two percent of respondents were working fulltime, $10 \%$ were working part-time, and $7 \%$ were not currently working. Participants' employment settings included: community hospital $24 \%$ of respondents, urban hospital 21\%, 4-year college/university $16 \%$, academic medical center $11 \%$, 2-year college $8 \%$, reference laboratory $6 \%$, physicians' office laboratory $4 \%$, industry $4 \%$, and other 6\%. Participants' job position/title included: technical staff $32 \%$ of respondents, educator $32 \%$, supervisor/manager $26 \%$, student 3\%, researcher 2\%, and other $6 \%$. Respondents' highest education levels included: B.S. 46\%, M.S. 33\%, Ph.D. 10\%, associate's degree 6\%, Ed.D 1\%, and other 4\%.

Research is a required employment component for 91 of $504(18 \%)$ of respondents. One to four hours per week is dedicated to research by $17 \%$ of respondents, and 5 to 12 hours is spent on research each week by $9 \%$. Thirteen to 20 hours per week are devoted to research by $2 \%$, and 21 to more than 35 hours are devoted to research each week by $3 \%$ of respondents. Sixty-eight percent of respondents reported spending zero time each week conducting research. Participants were asked to specify the total number of research projects in which they had participated during their careers as a principal investigator (PI) or co-PI and as a research contributor/team member. Four percent of survey respondents indicated that they had served as PI on 11 or more research projects, $2.7 \%$ had served as PI on 6 to 10 projects, $35 \%$ had been PI on 1 to 5 projects, and $58 \%$ had never served as PI. Six percent of survey respondents indicated that they had been a team member on 11 or more research projects, $8 \%$ had been a team member on 6 to 10 projects, $48 \%$ had been a team member on 1 to 5 projects, and $41 \%$ had never served as a contributor/team member for a research project. The numbers of participants' research publications and other publication types over the professional lifetime are contained in Table 1.

Participants were asked to rate the importance of conducting research by clinical laboratory professionals employed in a variety of positions. Conducting research was rated as moderately important, very important or extremely important for faculty in graduate degree programs by $92 \%$ of participants. Ratings of equal importance were attributed to faculty in baccalaureate degree programs by $79 \%$ of respondents and to faculty in medical laboratory technician programs by $57 \%$ of respondents. Conducting research as part of their jobs was rated as moderately, very, or extremely important for clinical laboratorians by $42 \%$ of respondents.

The most frequently cited barriers limiting or preventing research involvement by clinical laboratory professionals include: research not included in job description $65 \%$ of respondents, time constraints $62 \%$, lack of funding $44 \%$, no opportunity $37 \%$, and lack of space or equipment $36 \%$. Less frequently cited barriers to research participation include: lack of collaborators $26 \%$ of respondents, lack of graduate students $18 \%$, do not feel competent 15\%, insufficient access to statistical support $15 \%$, and lack of recognition for conducting research $13 \%$.

Table 1. Number of publications by type over professional lifetime. Data $=\%$ of respondents. $(\mathrm{N}=484)$

\begin{tabular}{|c|c|c|c|c|c|c|c|}
\hline \multirow[b]{3}{*}{ Research articles in professional journals } & \multirow{3}{*}{$\begin{array}{l}0 \\
70.6\end{array}$} & \multirow[b]{2}{*}{$1-2$} & \multicolumn{5}{|c|}{ Number of publications } \\
\hline & & & $3-4$ & $5-10$ & $11-25$ & $26-50$ & $>50$ \\
\hline & & 13.1 & 4.7 & 5.8 & 3.0 & 1.5 & 0.9 \\
\hline Abstracts in professional journals & 74.4 & 11.3 & 4.0 & 3.8 & 4.0 & 1.6 & 0.9 \\
\hline $\begin{array}{l}\text { Non-research articles in professional } \\
\text { journals and other publications }\end{array}$ & 63.9 & 19.2 & 6.6 & 6.8 & 2.4 & 0.2 & 0.7 \\
\hline Edited book chapters & 78.6 & 11.7 & 4.5 & 3.8 & 0.7 & 0.2 & 0.4 \\
\hline Books, manuals, and monographs & 85.5 & 9.3 & 1.9 & 1.9 & 1.2 & 0.0 & 0.2 \\
\hline Computer software & 92.1 & 4.8 & 1.9 & 0.5 & 0.2 & 0.2 & 0.2 \\
\hline Other & 89.2 & 4.8 & 2.6 & 0.9 & 1.3 & 1.3 & 0.4 \\
\hline
\end{tabular}




\section{FOCUS: BUILDING RESEARCH THROUGH MLS CURRICULA}

Respondents' non-research scholarly activities include preparing student lectures or instructional media $(60 \%$ of respondents), developing continuing education activities (57\%), writing non-research articles (38\%), preparing training grant applications (11\%), and "other" activities (6\%). Twenty-four percent of survey respondents indicated that they participate in no nonresearch scholarly activities. Table 2 shows the numbers of various types of scientific presentations given by respondents at international, national, regional, state, and local levels.

\section{Section 2. In-depth description of research activities}

The nine items in this section were directed to persons who were currently or had been actively engaged in research. The objectives were to characterize research in terms of general research type, specific areas of investigation, funding sources, amount of funding ob-

Table 2. Numbers and types of scientific presentations.

International Presentations
1. Major scientific research paper
2. Poster session on research
3. Non-research presentation (case study, scientific session, panel)
4. Web or audio

National

1. Major scientific research paper

2. Poster session on research

3. Non-research presentation (case study, scientific session, panel)

4. Web or audio

\section{Regional}

1. Major Scientific Research Paper

2. Poster Session on Research

3. Non-research Presentation (Case study, Scientific session, panel)

4. Web or Audio

\section{State}

1. Major scientific research paper

2. Poster session on research

3. Non-research presentation (case study, scientific session, panel)

4. Web or audio

\section{Local}

1. Major scientific research paper

2. Poster session on research

3. Non-research presentation (case study, scientific session, panel)

4. Web or audio

tained, and number of funded projects. When asked about the total number of externally funded research projects over their lifetimes, two (2\%) individuals indicated that they each had more than 50 projects. Eight $(7 \%)$ had 7 to 10 externally funded projects, 15 (13\%) had 3 to 6 , and $26(22 \%)$ indicated they had 1 to 2 externally funded projects. Sixty-seven (57\%) participants indicated that they had conducted no externally funded research projects during their professional careers. Three of 117 respondents (2.6\%) indicated that $100 \%$ of their salary was dependent on research funding. Two respondents stated that their

$\begin{array}{rrrrc}0 & \mathbf{1 - 2} & \mathbf{3 - 4} & \mathbf{5 - 1 0} & \begin{array}{c}\text { Total } \\ \text { Presentations }\end{array} \\ 106 & 12 & 5 & 5 & 22 \\ 91 & 15 & 6 & 2 & 23 \\ 86 & 18 & 7 & 2 & 27 \\ 101 & 5 & 3 & 0 & 8\end{array}$

$\begin{array}{rrrrr}91 & 25 & 13 & 7 & 45 \\ 75 & 49 & 22 & 15 & 86 \\ 67 & 47 & 18 & 22 & 87 \\ 86 & 21 & 8 & 7 & 36\end{array}$

$\begin{array}{rrrrr}99 & 12 & 4 & 3 & 19 \\ 91 & 15 & 7 & 3 & 25 \\ 63 & 45 & 19 & 13 & 77 \\ 91 & 6 & 1 & 1 & 8\end{array}$

$\begin{array}{rrrrr}94 & 18 & 7 & 3 & 28 \\ 91 & 25 & 6 & 2 & 33 \\ 50 & 51 & 31 & 27 & 109 \\ 95 & 9 & 3 & 3 & 15\end{array}$

$\begin{array}{rrrrr}100 & 23 & 4 & 4 & 31 \\ 83 & 28 & 5 & 3 & 36 \\ 37 & 57 & 32 & 30 & 119 \\ 205 & 7 & 3 & 0 & 10\end{array}$

salaries would be lowered if they have no research funding, and 112 answered that none of their salary was linked to research or declined to respond.

Applied or clinical research is the general type of research conducted by $49 \%$ of the 134 participants. Additional types included educational research (36\%), a combination of basic and applied topics (20\%), basic science research (13\%), and other (4\%). Principle areas of investigation are listed as microbiology by $22 \%$ of survey respondents, education by $16 \%$, clinical chemistry by $10 \%$, immunology by $10 \%$, 


\section{FOCUS: BUILDING RESEARCH THROUGH MLS CURRICULA}

hematology/hemostasis by $7 \%$, new instrumentation methods by $7 \%$, cancer by $3 \%$, drugs/antibiotics by $3 \%$, blood bank by $3 \%$, genetics by $2 \%$, proficiency/quality assurance by $2 \%$, and other by $16.0 \%$.

Almost half of respondents (48\%) indicated that they had published their research in the journal Clinical Laboratory Science. Other journals in which the researchers' articles were published include: Laboratory Medicine (17\%), Journals of the American Society for Microbiology (15\%), American Journal of Clinical Pathology (12\%), Clinical Chemistry (11\%), Blood (4\%), Archives of Pathology and Laboratory Medicine (3\%), and Transfusion (2\%). Over half of respondents $(52 \%)$ indicated that they had published their research in journals other than those listed.

Seventy-six percent of survey respondents indicated that they had received research funding from their own institution. Other research funding sources included: government (federal, state, and local) $46 \%$ of respondents, private (foundations, alumni, self) 36, professional organizations $18 \%$, and other $4 \%$. Total amounts of funding obtained for research over the lifetime are contained in Table 3. The total sum of research funding for all respondents was $\$ 16,757,300$. Table 4 indicates total and mean funding amounts for CLS professionals at varying educational levels. Eleven percent of respondents reported that 76 to $100 \%$ of their submitted proposals were funded, $8 \%$ had 51 to $75 \%$ of proposals funded, $12 \%$ had 26 to $50 \%$ of proposals funded, and $16 \%$ had up to $25 \%$ of proposals funded. Over half of respondents (52\%) indicated that $0 \%$ of submitted research proposals were funded.

\section{DISCUSSION}

It is clear from the results of this survey that CLS professionals are conducting research, presenting their research findings, and publishing their studies in a variety of well-respected journals related to the field. Almost one-third of respondents reported that they currently spend a portion of each week conducting research. Furthermore, survey results indicate that over $61 \%$ of participants have served as a research team member and almost $42 \%$ have served as a principal or co-investigator on at least one project during their professional careers. Twenty-nine percent of survey participants have published research articles in professional journals. Although the amount of time spent weekly on research varies greatly among respondents, the total number of persons engaged in research is somewhat surprising given that research is a current employment requirement for only $18 \%$ of respondents. Sixty-five percent of survey participants indicated that research is not included in their job descriptions.

Table 3. Total amount of research funding obtained over professional lifetime. $(\mathrm{N}=112)$

\begin{tabular}{lcc}
\hline Funding amount, \$ & Frequency & $\%$ \\
0 & 59 & 52.7 \\
$<10,000$ & 14 & 12.5 \\
$10,000-50,000$ & 14 & 12.5 \\
$50,001-100,000$ & 7 & 6.2 \\
$100,001-250,000$ & 6 & 5.4 \\
$>250,000$ & 12 & 10.7 \\
\hline
\end{tabular}

Table 4. Research funding received according to respondent's highest educational level.

\begin{tabular}{lrrr}
\hline $\begin{array}{l}\text { Highest degree } \\
\text { obtained funding } \\
\text { (number of }\end{array}$ & $\begin{array}{c}\text { Total funding } \\
\text { amount, } \$\end{array}$ & $\begin{array}{c}\text { Mean funding } \\
\text { amount, } \$\end{array}$ & $\begin{array}{l}\% \text { of } \\
\text { total }\end{array}$ \\
$\begin{array}{l}\text { respondents) } \\
\text { Ph.D. (41) }\end{array}$ & $15,560,000$ & 379,512 & 92.8 \\
Ed.D. (4) & 381,000 & 95,250 & 2.3 \\
M.S. (33) & 737,500 & 21,676 & 4.4 \\
B.S. (27) & 68,800 & 2,548 & 0.4 \\
Associate degree (2) & 10,000 & 5,000 & $<0.1$ \\
Total & $16,757,300$ & $-\cdots$ & 100 \\
\hline
\end{tabular}

Results of this survey also document the array of funding sources used and total amounts of funding obtained by clinical laboratory professionals over their professional lifetimes, indicating that at least historically, funding for research has been available to them. Respondents indicated that of their submitted proposals, slightly more than $47 \%$ were funded. This should offer encouragement to others who may be discouraged by negative perceptions of funding availability. It is also evident that clinical laboratory professionals conduct research in a variety of areas of concentration within the discipline and have experienced success in publishing their studies in many peer-reviewed journals. 


\section{FOCUS: BUILDING RESEARCH THROUGH MLS CURRICULA}

Survey participants were asked to indicate barriers limiting or preventing their involvement in research. The top six factors, each of which were identified as influencing at least $25 \%$ of the respondents, included research not included in job description (65\%), time constraints (62\%), lack of funding (44\%), no opportunity (37\%), lack of space or equipment (36\%), and lack of collaborators (26\%). Fifteen percent of respondents indicated that they do not feel competent in the area of research. These results suggest that for a significant portion of clinical laboratory professionals, an expectation for research engagement on the job is unrealistic.

In addition to research activities, data from this study indicate that CLS professionals are engaged in nonresearch based scholarly activities, including preparing student lectures, instructional media, and continuing education presentations, and writing non-research articles such as review papers and training grant applications. The high levels of participation in these activities support the inclusive approach to scholarship taken by Ernest Boyer and Riley and colleagues.

The expectation for a higher level of research skills by clinical laboratory professionals with advanced degrees is not surprising. Data from this study confirm that professionals with a Ph.D. bring in the greatest portion, $93 \%$, of research funding. The mean funding amount for professionals with a master's degree is eight times more than the mean funding amount for those with only a B.S. degree. These results are consistent with those of Waller et al who found that faculty holding the doctoral degree spent more time doing research and received more funding than those with master's or baccalaureate degrees.

There are some data from this study to support an emphasis on research engagement by CLS professionals. Over $40 \%$ of respondents rated conducting research as moderately, very, or extremely important by clinical laboratorians as part of their jobs, and much higher numbers gave similar importance ratings to CLS faculty research. These findings support those of Mundt and Shanahan who reported that $75 \%$ of laboratory professionals believe they have the responsibility to conduct research and to publish and present their findings. Integrating more time for research activities into many jobs held by CLS professionals, including program faculty, will be a significant challenge.

The authors recognize some limitations of this study. Although there was broad representation among participants across educational levels, employment settings, and job positions, the number of survey respondents was limited to only $7 \%$. It is also noteworthy that data analysis described in this paper is at the descriptive level, with no t-tests or ANOVAs performed. Advanced statistical analysis could show more relationships; for example, it would be interesting to know if educators perceive research as more important to the profession than do clinical laboratory staff.

This study assessed the research activities of only ASCLS members and program directors. To gain a more complete assessment of research activity among clinical laboratory professionals, the survey could be sent to members of additional organizations, including the American Society for Microbiology, American Association for Clinical Chemistry, American Society for Clinical Pathology, and others. This would target clinical laboratory professionals who are not members of ASCLS but are members of other professional societies and who may engage in research and scholarly activities. This could result in both a broader perspective on research activities and possibly increase the number of survey respondents.

Findings from this study suggest that CLS professionals believe in the importance of research, are engaged in research in numbers that vary by job position and other factors, but are more likely to engage in non-research types of scholarly activities than in research. Additional studies using a more inclusive sample and building on these preliminary findings are needed.

\section{REFERENCES}

1. Personal communication Scott Aikey 10/11/2008.

2. Waller KV, Clutter JE, Karni KR. Research and scholarship of clinical laboratory science faculty members. Clin Lab Sci 2010;23 Suppl:3-32-8.

3. Mundt L, Shanahan K. ASCLS members' perceptions regarding research. Clin Lab Sci 2009;22:170-5.

4. Smesny AL, Williams JS, Brazeau GA, et al. Barriers to scholarship in dentistry, medicine, nursing, and pharmacy practice faculty. Am J Phar Educ 2007;71;91-7.

5. Riley JM, Beal J, Levi P, McCausland MP. Revisioning nursing scholarship. J Nursing Scholarship 2002;34:3839. 
6. Fonteyn M, McDonough K, Salazar R, Bauer-Wu S. Support for frontline oncology nurses' and administrators' scholarly activities. Oncol Nurs Forum 2006;33:1061-3.
7. Boyer EL. 1990. Scholarship reconsidered: Priorities of the professorate. Princeton NJ: Carnegie Endowment for the Advancement of Teaching.

\section{Purchase the recorded versions of the 2011 AsCls Annual Meeting}

\section{Earn P.A.C.E. credit by January 31, 20121}

Puchase and watch the recorded education presentations from the 2011 ASCLS Annual Meeting by January 31, 2012 and earn P.A.C.E. credit

Experience scientific sessions presented as synchronized slides and audio.

Purchase the Complete Conference Package

Download MP3 files - $\$ 149$

CD-ROM - \$169 plus shipping

Purchase Individual Sessions

Download MP3 file - $\$ 20 /$ session

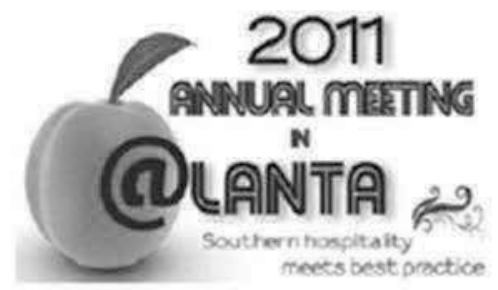

For more information, go to http://www.ascls.org/?ASCLSemeeting 